\title{
Association between metabolic syndrome and venous thromboembolism after total joint arthroplasty: a meta-analysis of cohort studies
}

Yipei Yang ${ }^{1}$, Ziyue Li ${ }^{2}$, Haifeng Liang ${ }^{1}$ and Jing $\operatorname{Tian}^{1^{*}}$ (D)

\begin{abstract}
Objective: Metabolic syndrome (MetS) has been associated with hypercoagulative status. However, previous studies evaluating the association between MetS and incidence of venous thromboembolism (VTE) after total joint arthroplasty (TJA) showed inconsistent results. We performed a meta-analysis to evaluate the influence of MetS on the risk of VTE following TJA.

Methods: Cohort studies were identified by the search of PubMed, Embase, and the Cochrane's Library databases. A random-effect model was used if considerable heterogeneity was detected; otherwise, a fixed-effect model was used. Subgroup analyses according to the category of VTE, definition of MetS, category of procedure, and follow-up durations were performed.
\end{abstract}

Results: Seven cohort studies with 1,341,457 patients that underwent TJA were included, with 118,060 MetS patients (8.8\%) at baseline. With a follow-up duration up to 3 months after surgery, 9788 patients had VTE. Pooled results with a random-effect model showed that MetS was not associated with increased overall VTE after TJA (adjusted risk ratio $[R R]=1.24,95 \%$ confidence interval $[\mathrm{CI}] 0.89 \sim 1.72, p=0.20 ; l^{2}=69 \%$ ). The results were not significantly affected by the diagnostic criteria of MetS, category of the procedure, and follow-up durations. Subgroup analyses showed that MetS was not associated with an increased the risk of pulmonary embolism ([PE], RR 1.06, 95\% Cl $0.37 \sim 3.02, p=0.91$ ), but an increased risk of deep vein thrombosis (DVT) after TJA (RR 3.38, 95\% Cl $1.83 \sim 6.24, p<0.001)$.

Conclusions: Current evidence from observational studies suggests MetS might be associated with an increased risk of DVT but not PE after TJA.

Keywords: Metabolic syndrome, Total knee arthroplasty, Total hip arthroplasty, Venous thromboembolism, Metaanalysis

\footnotetext{
*Correspondence: tianjing_ortho@163.com

'Department of Orthopedic and Joint Surgery, Zhu Jiang Hospital, Southern

Medical University, No. 253 Middle Gongye Dadao, Haizhu District,

Guangzhou 510000, China

Full list of author information is available at the end of the article
}

C C The Author(s). 2020 Open Access This article is licensed under a Creative Commons Attribution 4.0 International License, which permits use, sharing, adaptation, distribution and reproduction in any medium or format, as long as you give appropriate credit to the original author(s) and the source, provide a link to the Creative Commons licence, and indicate if changes were made. The images or other third party material in this article are included in the article's Creative Commons licence, unless indicated otherwise in a credit line to the material. If material is not included in the article's Creative Commons licence and your intended use is not permitted by statutory regulation or exceeds the permitted use, you will need to obtain permission directly from the copyright holder. To view a copy of this licence, visit http://creativecommons.org/licenses/by/4.0/ The Creative Commons Public Domain Dedication waiver (http://creativecommons.org/publicdomain/zero/1.0/) applies to the data made available in this article, unless otherwise stated in a credit line to the data. 


\section{Introduction}

Patients undergoing total joint arthroplasty (TJA), including total knee arthroplasty (TKA) and total hip arthroplasty (THA), are at a higher risk for the development of venous thromboembolism (VTE) [1-3]. Despite the routine use of prophylactic measures against thrombosis in these patients, the incidences of VTE, including pulmonary embolism (PE) and deep vein thrombosis (DVT) remains high [4]. A previous systematic review including 44,844 cases from 47 studies showed that in patients receiving recommended prophylaxis, the pooled rates of symptomatic postoperative VTE before hospital discharge were $1.09 \%$ for patients undergoing TKA and $0.53 \%$ for those undergoing THA [5]. Moreover, VTE has become an important cause of morbidity and mortality in patients after TJA [6]. Identification of risk factors for VTE in patients that received TJA is clinically important [6].

Metabolic syndrome (MetS) refers to a cluster of metabolic abnormalities including abdominal adiposity, insulin resistance, hyperglycemia, hypertension, and dyslipidemia $[7,8]$. Accumulating evidence suggests that patients MetS are characterized by hypercoagulative status [9-13]. Indeed, MetS has been associated with a 2-fold increase in arterial thrombotic diseases, such as coronary artery disease and stroke [14]. Moreover, a previous individual-patient data-based meta-analysis showed that MetS is associated with an increased risk of unprovoked VTE in general population [15]. Since MetS is prevalent in patients undergoing TJA, accumulating studies have evaluated the association between MetS and risk of VTE in these patients [16-22]. However, the results of these studies are inconsistent. Some of them suggested that MetS may be a risk factor for VTE after TJA [16, 19, $21]$, while other studies did not $[17,18,20,22]$. Therefore, we aimed to perform a meta-analysis to evaluate the association between MetS and risk of VTE in patients after TJA. The influences of categories of VTE, definitions of MetS, and types of procedures on the association were also analyzed.

\section{Methods}

The meta-analysis was designed and performed in accordance with the MOOSE (Meta-analysis of Observational Studies in Epidemiology) [23] and Cochrane's Handbook [24] guidelines.

\section{Literature search}

Electronic databases of PubMed, Embase, and the Cochrane's Library were systematically searched using the combination of the following terms: [1] "metabolic syndrome" OR "insulin resistance syndrome" OR "syndrome X" [2]; "hip" OR "knee"; and [3] "arthroplasty" OR "replacement" OR "surgery" OR "operation". We used this extensive search strategy to avoid missing potential studies. The search was limited to human studies published in English or Chinese. The reference lists of original and review articles were also analyzed manually. The final literature search was performed on April 2, 2020.

\section{Study selection}

Studies were included if they met the following criteria: [1] published as full-length article, [2] designed as cohort studies, [3] included patients that received TKA or THA, [4] MetS was identified as exposure of interest at baseline, [5] documented the incidence of any VTE events (overall VTE, PE, or DVT) in patients with and without MetS, and [6] reported the adjusted risk ratios (RRs, at least adjusted for age and sex) and their corresponding 95\% confidence intervals (CIs) for the incidence of VTE in patients with and without MetS. Definitions of MetS were consistent with what was applied in the original studies. Reviews, editorials, preclinical studies, and non-cohort studies were excluded.

\section{Data extracting and quality evaluation}

Literature search, data extraction, and study quality assessment were independently performed by two authors according to the predefined inclusion criteria. If inconsistencies occurred, discussion with the corresponding author was suggested to resolve the disagreement. The following data were extracted: [1] name of the first author, publication year, study location, and study design [2]; characteristics and numbers of patients that received TKA or THA, criteria for the diagnosis of MetS, prevalence of MetS, and follow-up period; and [3] number of cases with any VTE events during follow-up, VTE prophylactic strategies, methods for the validation of the outcome, and variables adjusted. The quality of each study was evaluated using the Newcastle-Ottawa Scale (NOS) [25]. This scale ranges from 1 to 9 stars and judges the quality of each study regarding three aspects: the selection of the study groups, the comparability of the groups, and the ascertainment of the outcome of interest.

\section{Statistical analyses}

The association between MetS and VTE in patients after TKA or THA was measured by RRs. To stabilize its variance and normalized the distribution, RR data and its corresponding stand error (SE) from each study was logarithmically transformed [24]. The Cochrane's $Q$ test was performed to evaluate the heterogeneity among the include cohort studies [24, 26], and the $I^{2}$ statistic was also calculated. A significant heterogeneity was considered if $I^{2}>50 \%$. A random effect model was used to pool the results if significant heterogeneity was detected; 
otherwise, a fixed-effect model was used. Sensitivity analysis by omitting one study at a time was performed to evaluate the stability of the results [24]. To evaluate the influences of categories of VTE, definitions of MetS, types of procedures, and follow-up durations on the association, subgroup analyses were performed. Potential publication bias was assessed by visual inspection of the symmetry of the funnel plots, complemented with the Egger regression test [27]. $P<0.05$ was considered as statistically significant. The RevMan (Version 5.1; Cochrane Collaboration, Oxford, UK) and STATA software were used for the statistics.

\section{Results}

Literature search

The flowchart of the database search was shown in Fig. 1. Briefly, 788 studies were obtained from the database search, and 768 of them were excluded primarily due to the irrelevance to the purpose of the study. For the remaining 20 potential relevant studies that underwent full-text review, 13 were further excluded for the reasons listed in Fig. 1. Finally, seven cohort studies were included [16-22].

\section{Study characteristics and quality}

Characteristics of the included studies were summarized in Table 1. Overall, seven cohort studies with 1,341,457 patients that underwent TJA were included [16-22]. These studies were performed in the USA, Canada, and China and published between 2009 and 2018. One of them was a prospective cohort study [16], and the others were retrospective cohorts [17-22]. Since two studies reported the incidence of VTE events in patients received TKA and THA separately, these datasets were independently included. Therefore, nine datasets were available for the meta-analysis, and 118,060 patients $(8.8 \%)$ were diagnosed as MetS at baseline according to the World Health Organization (WHO) [16, 20, 21] or the National Cholesterol Education Program Expert Panel and Adult Treatment Panel III (NCEP-ATP III) criteria [1719, 22]. The follow-up duration varied between within hospitalization and 3 months after surgeries, and 9788 patients had VTE during follow-up. Strategies for VTE prophylaxis were reported in three studies [16, 19, 21], and anticoagulants of warfarin, rivaroxaban, or low-molecularweight heparin were used. The methods for VTE assessment were also reported in three studies [16, 19, 21], which involved the application of Doppler ultrasonography, venography, and CT and/or lung VQ scan. Potential confounding factors, including age, sex, body mass index (BMI), smoking, and comorbidities, were adjusted to a varying degree in the included studies. The qualities of the included follow-up studies were generally good, with the NOS ranging from $6 \sim$ 8 (Table 2).

\section{Association between MetS and VTE after TJA}

Significant heterogeneity was detected among the studies that evaluated the association between MetS and VTE

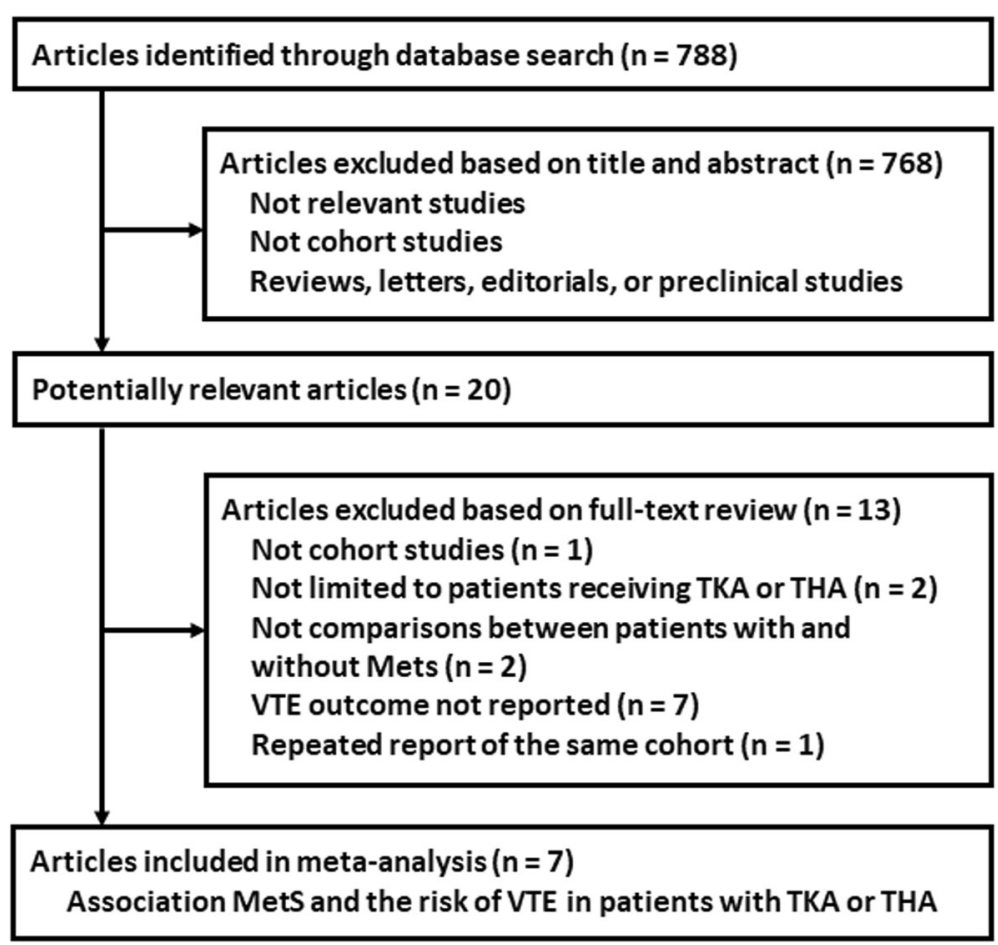

Fig. 1 The flowchart of database search and study inclusion 


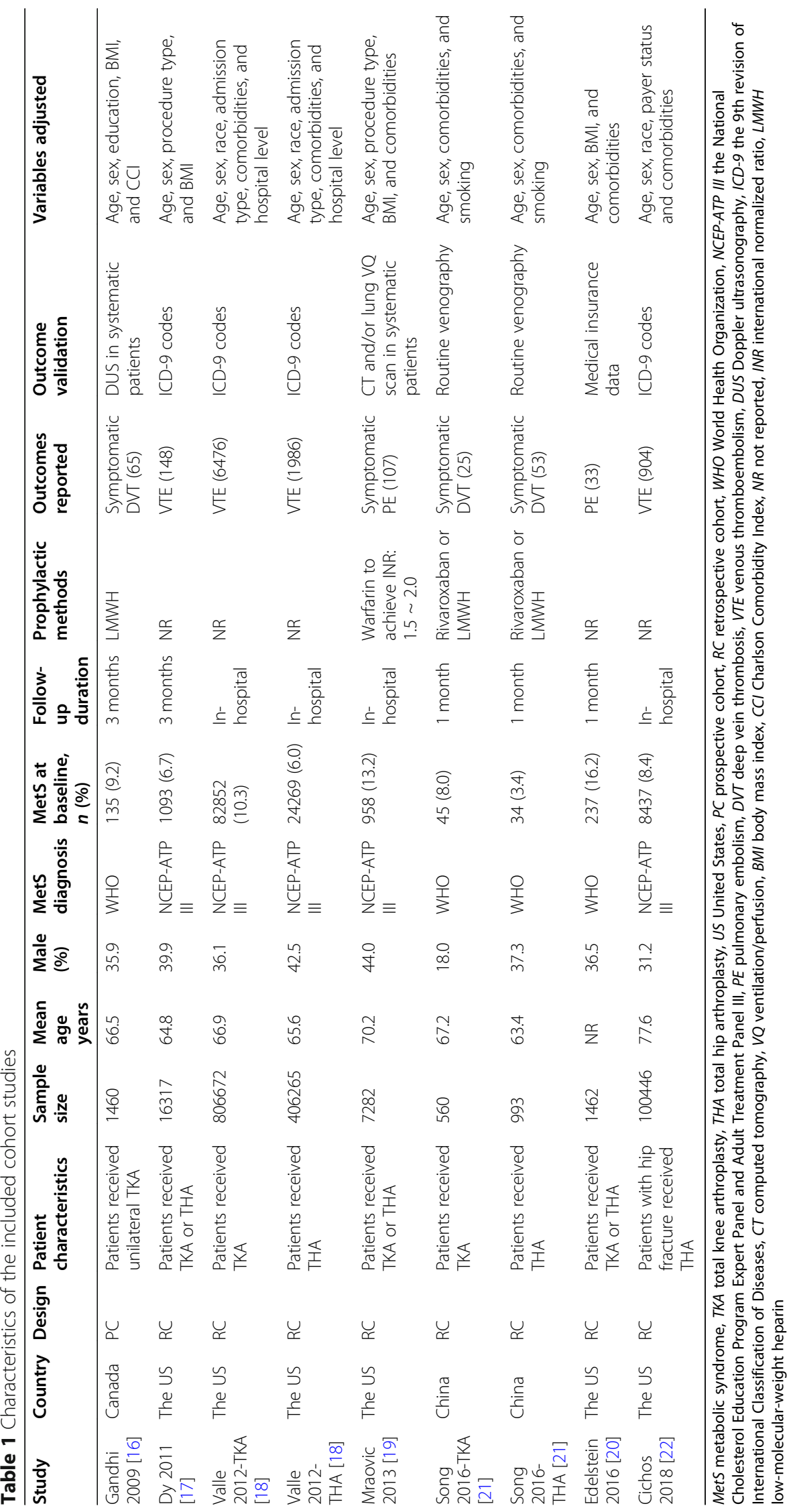


Table 2 Details of the study quality evaluation via the Newcastle-Ottawa Scale

\begin{tabular}{|c|c|c|c|c|c|c|c|c|c|c|}
\hline Study & $\begin{array}{l}\text { Representativeness } \\
\text { of the exposed } \\
\text { cohort }\end{array}$ & $\begin{array}{l}\text { Selection } \\
\text { of the } \\
\text { non- } \\
\text { exposed } \\
\text { cohort }\end{array}$ & $\begin{array}{l}\text { Ascertainment } \\
\text { of exposure }\end{array}$ & $\begin{array}{l}\text { Outcome } \\
\text { not } \\
\text { present } \\
\text { at } \\
\text { baseline }\end{array}$ & $\begin{array}{l}\text { Control } \\
\text { for age } \\
\text { and sex }\end{array}$ & $\begin{array}{l}\text { Control for } \\
\text { other } \\
\text { confounding } \\
\text { factors }\end{array}$ & $\begin{array}{l}\text { Assessment } \\
\text { of outcome }\end{array}$ & $\begin{array}{l}\text { Enough } \\
\text { long } \\
\text { follow- } \\
\text { up } \\
\text { duration }\end{array}$ & $\begin{array}{l}\text { Adequacy } \\
\text { of follow- } \\
\text { up of } \\
\text { cohorts }\end{array}$ & Total \\
\hline $\begin{array}{l}\text { Gandhi } \\
2009 \text { [16] }\end{array}$ & 1 & 1 & 1 & 0 & 1 & 1 & 1 & 1 & 1 & 8 \\
\hline $\begin{array}{l}\text { Dy } 2011 \\
{[17]}\end{array}$ & 0 & 1 & 1 & 0 & 1 & 0 & 1 & 1 & 1 & 6 \\
\hline $\begin{array}{l}\text { Valle } \\
\text { 2012-TKA } \\
{[18]}\end{array}$ & 0 & 1 & 1 & 0 & 1 & 1 & 1 & 0 & 1 & 6 \\
\hline $\begin{array}{l}\text { Valle } \\
\text { 2012- } \\
\text { THA [18] }\end{array}$ & 0 & 1 & 1 & 0 & 1 & 1 & 1 & 0 & 1 & 6 \\
\hline $\begin{array}{l}\text { Mraovic } \\
2013 \text { [19] }\end{array}$ & 0 & 1 & 1 & 0 & 1 & 1 & 1 & 0 & 1 & 6 \\
\hline $\begin{array}{l}\text { Song } \\
\text { 2016-TKA } \\
{[21]}\end{array}$ & 0 & 1 & 1 & 1 & 1 & 1 & 1 & 1 & 1 & 8 \\
\hline $\begin{array}{l}\text { Song } \\
\text { 2016- } \\
\text { THA [21] }\end{array}$ & 0 & 1 & 1 & 1 & 1 & 1 & 1 & 1 & 1 & 8 \\
\hline $\begin{array}{l}\text { Edelstein } \\
2016 \text { [20] }\end{array}$ & 0 & 1 & 1 & 0 & 1 & 1 & 1 & 1 & 1 & 7 \\
\hline $\begin{array}{l}\text { Cichos } \\
2018 \text { [22] }\end{array}$ & 0 & 1 & 1 & 0 & 1 & 1 & 1 & 0 & 1 & 6 \\
\hline
\end{tabular}

This Newcastle-Ottawa Scale ranges from 1 to 9 stars and judges the quality of each study regarding the nine domains as listed in the table, with higher scores indicating better study quality

risk after TJA (P for Cochrane's $Q$ test $=0.001, I^{2}=$ $69 \%)$. Pooled results with a random-effect model showed that MetS was not associated with increased overall VTE after TJA (adjusted $\mathrm{RR}=1.24,95 \%$ CI $0.89 \sim 1.72, p=$ $0.20 ; I^{2}=69 \%$; Fig. 2a). Sensitivity analysis by excluding one study at a time did not significantly affect the results (Table 3). Subgroup analyses showed that MetS was not associated with an increased the risk of PE (RR 1.06, 95\% CI $0.37 \sim 3.02, p=0.91$ ) or VTE (RR 0.91, 95\% CI $0.80 \sim 1.04, p=0.16)$, but with an increased risk of DVT after TJA (RR 3.38, 95\% CI $1.83 \sim 6.24, p<0.001 ; p$ for subgroup difference $<0.001$; Fig. $2 b$ ). Further studies showed that MetS was not significantly associated with an increased risk of VTE after TJA in studies with MetS diagnosed with WHO ( $\mathrm{RR}=2.18,95 \%$ CI $0.91 \sim 5.22, p$ $=0.08)$ or NCEP-ATP III criteria $(\mathrm{RR}=0.99,95 \% \mathrm{CI}$ $0.77 \sim 1.27, p=0.95$; Fig. 3a), in studies of patients received TKA ( $\mathrm{RR}=2.04,95 \%$ CI $0.66 \sim 6.34, p=0.22$ ), THA (RR $=1.05,95 \%$ CI $0.52 \sim 2.10, p=0.90)$, or both $(\mathrm{RR}=1.29,95 \% \mathrm{CI} 0.71 \sim 2.34, p=0.41$; Fig. 3b), and in studies of follow-up within hospitalization $(\mathrm{RR}=0.97$, $95 \%$ CI $0.75 \sim 1.26, p=0.83), 1$ month $(\mathrm{RR}=1.95,95 \%$ CI $0.60 \sim 6.34, p=0.27$ ), and 3 months $(\mathrm{RR}=2.16,95 \%$ CI $0.94 \sim 4.98, p=0.07$; Fig. 4) after JTA.

\section{Publication bias}

The funnel plots for the association between MetS and VTE after TKA or THA were shown in Fig. 5. The plots were symmetrical on visual inspection, suggesting low risks of publication biases. Results of Egger's regression tests also showed similar results $(p=0.389)$.

\section{Discussion}

In this meta-analysis of cohort study, we found that MetS at baseline was not associated with an increased risk of overall VTE events in patients after TJA. Subgroup analysis showed that MetS was independently associated with an increased risk of DVT, but not PE in patients after TJA. Moreover, the results were not significantly affected by the diagnostic criteria of MetS, the types of surgical procedures, and the follow-up durations. Taken together, current evidence from observational studies suggests that MetS might be associated with an increased risk of DVT, but not PE in patients after TJA.

To the best of our knowledge, our study is the first meta-analysis to evaluate the potential association between MetS and VTE risk in patients after TJA. Although we did not show that MetS was independently 


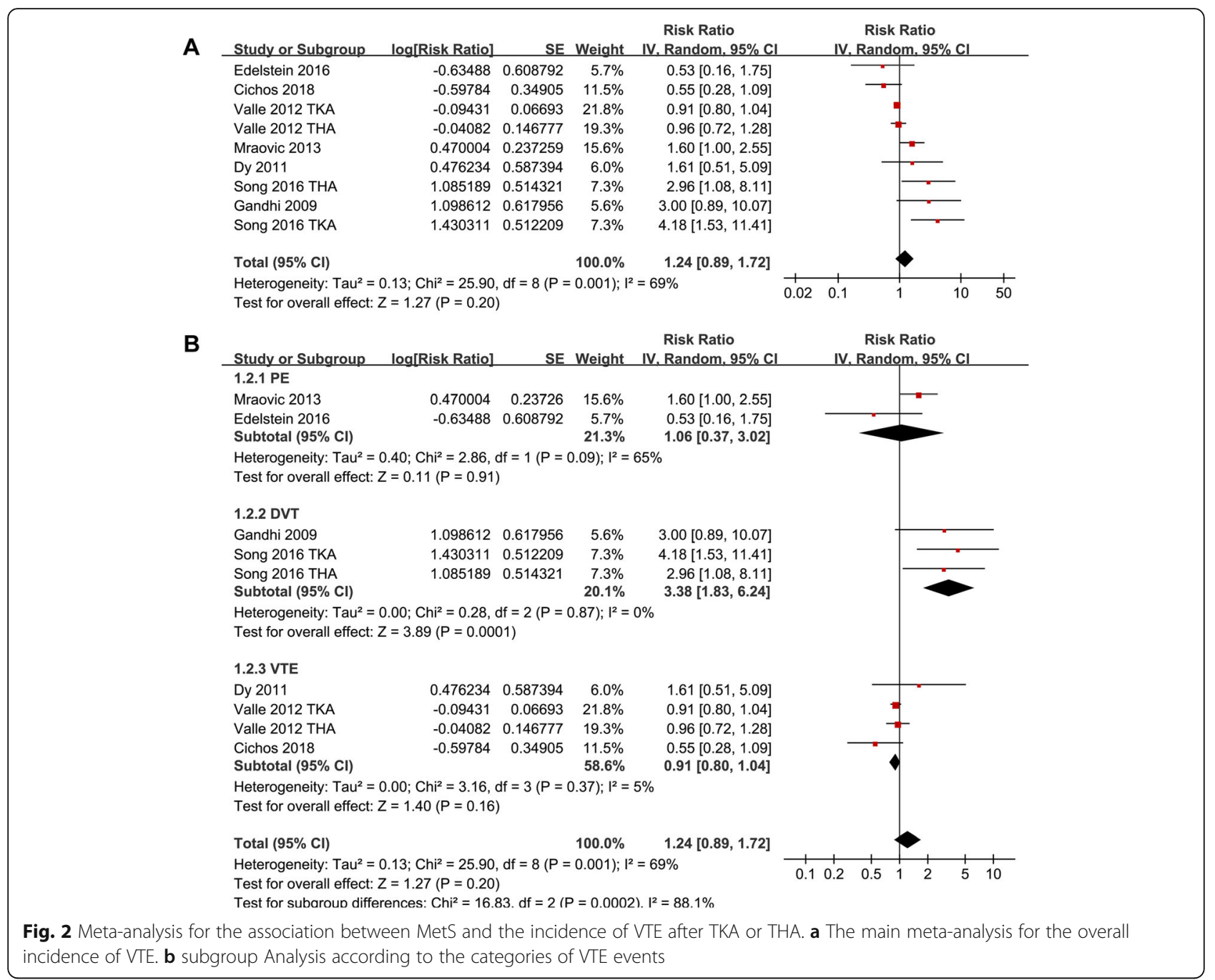

associated with an increased incidence of overall VTE, subgroup analysis suggests that MetS was associated with an increased risk of DVT but not PE in these patients. The potential reasons for the findings remain unknown. Generally, PE was resulted by thrombi from the

Table 3 Results of sensitivity analysis

\begin{tabular}{lllll}
\hline Studies omitted & RR & 95\% Cl & $\boldsymbol{I}^{\mathbf{2}}$ & $\boldsymbol{P}$ for effect \\
\hline Gandhi 2009 [16] & 1.17 & 0.84 to 1.62 & $69 \%$ & 0.35 \\
Dy 2011 [17] & 1.22 & 0.86 to 1.72 & $72 \%$ & 0.26 \\
Valle 2012-TKA [18] & 1.40 & 0.89 to 2.22 & $68 \%$ & 0.15 \\
Valle 2012-THA [18] & 1.38 & 0.87 to 2.17 & $73 \%$ & 0.17 \\
Mraovic 2013 [19] & 1.18 & 0.82 to 1.68 & $67 \%$ & 0.37 \\
Song 2016-TKA [21] & 1.10 & 0.82 to 1.48 & $61 \%$ & 0.53 \\
Song 2016-THA [21] & 1.14 & 0.83 to 1.58 & $67 \%$ & 0.41 \\
Edelstein 2016 [20] & 1.31 & 0.93 to 1.84 & $72 \%$ & 0.13 \\
Cichos 2018 [22] & 1.37 & 0.95 to 1.98 & $70 \%$ & 0.10 \\
\hline
\end{tabular}

$R R$ risk ratio, $\mathrm{Cl}$ confidence interval lower extremities of patients with DVT. Due to the routine use of prophylactic measures against VTE in patients after TJA, the incidence of PE in these patients is lower than the incidence of DVT [28]. In our study, the pooled incidence of DVT was $4.7 \%$ and compared to $1.6 \%$ for PE. It could be hypothesized that potential differences in patient characteristics or diagnostic strategies may be responsible for the observed different associations between MetS with DVT and PE. However, limited datasets included in the subgroup analysis prevented further analysis. Moreover, we found that the results were not significantly affected by the diagnostic criteria of MetS or the types of surgical procedures. Previous studies showed that patients after TKA seem to have a higher incidence of VTE events than those after THA [5, 28]. Although the overall meta-analysis did not show a significant association between MetS and VTE after TJA, subgroup analysis suggested that MetS was associated with increased DVT after TJA. Since only three datasets were included in the subgroup analysis of DVT events, 


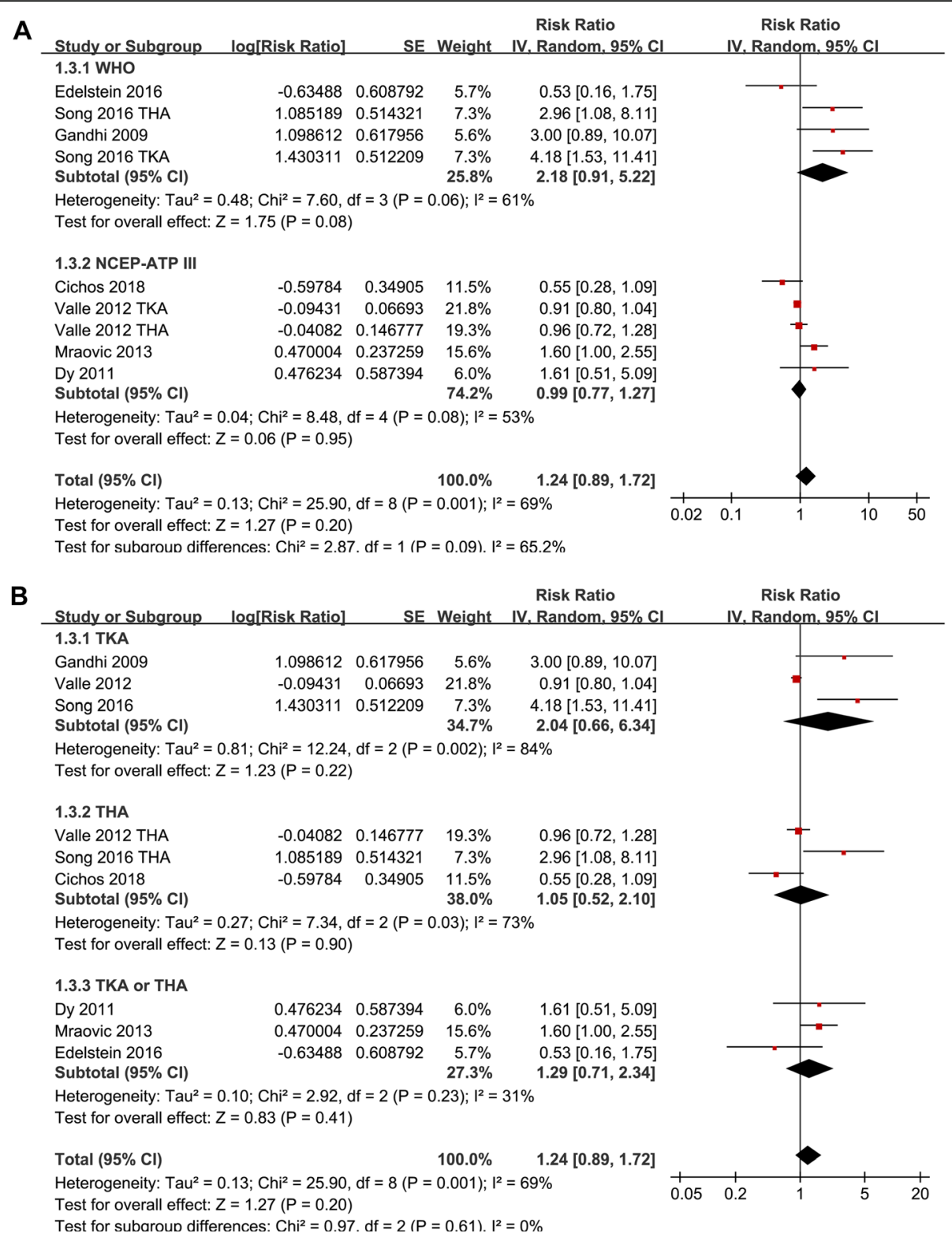

Fig. 3 Subgroup analyses the association between MetS and the incidence of VTE after TKA or THA. a Subgroup analysis according to the diagnostic criteria of MetS. b Subgroup analysis according to the types of surgical procedures

the findings should be validated in large-scale prospective studies. A previous case-control study showed that patients with uncontrolled MetS had a significantly higher incidence of VTE after TJA compared to patients without MetS, while those with controlled MetS had a similar risk of VTE compared to patients without MetS [29], and the VTE events occurred were mainly DVT. These findings may suggest the importance of MetS control for the reducing the risk of DVT after TJA.

The potential pathophysiological mechanisms underlying the association between MetS and increased risk of DVT after TJA may be multifactorial. Patients with MetS are characterized by a persistent activated chronic inflammatory response. Since inflammation is a major activator of coagulation, these patients are generally at hypercoagulative status, thereby vulnerable to venous thrombosis [10, 11]. Moreover, it has been shown that patients with MetS have impaired spontaneous thrombolytic activity as reflected by an impaired expression of tissue-type plasminogen activator [30], which may also be involved in their vulnerability to thrombotic events. Besides, patients with MetS tend to be overnutrition and are more likely to be exposed to high-fat diet. Previous studies showed that high-fat diet maintains high endogenous thrombin potential, which is associated with venous and arterial thrombosis independently of 


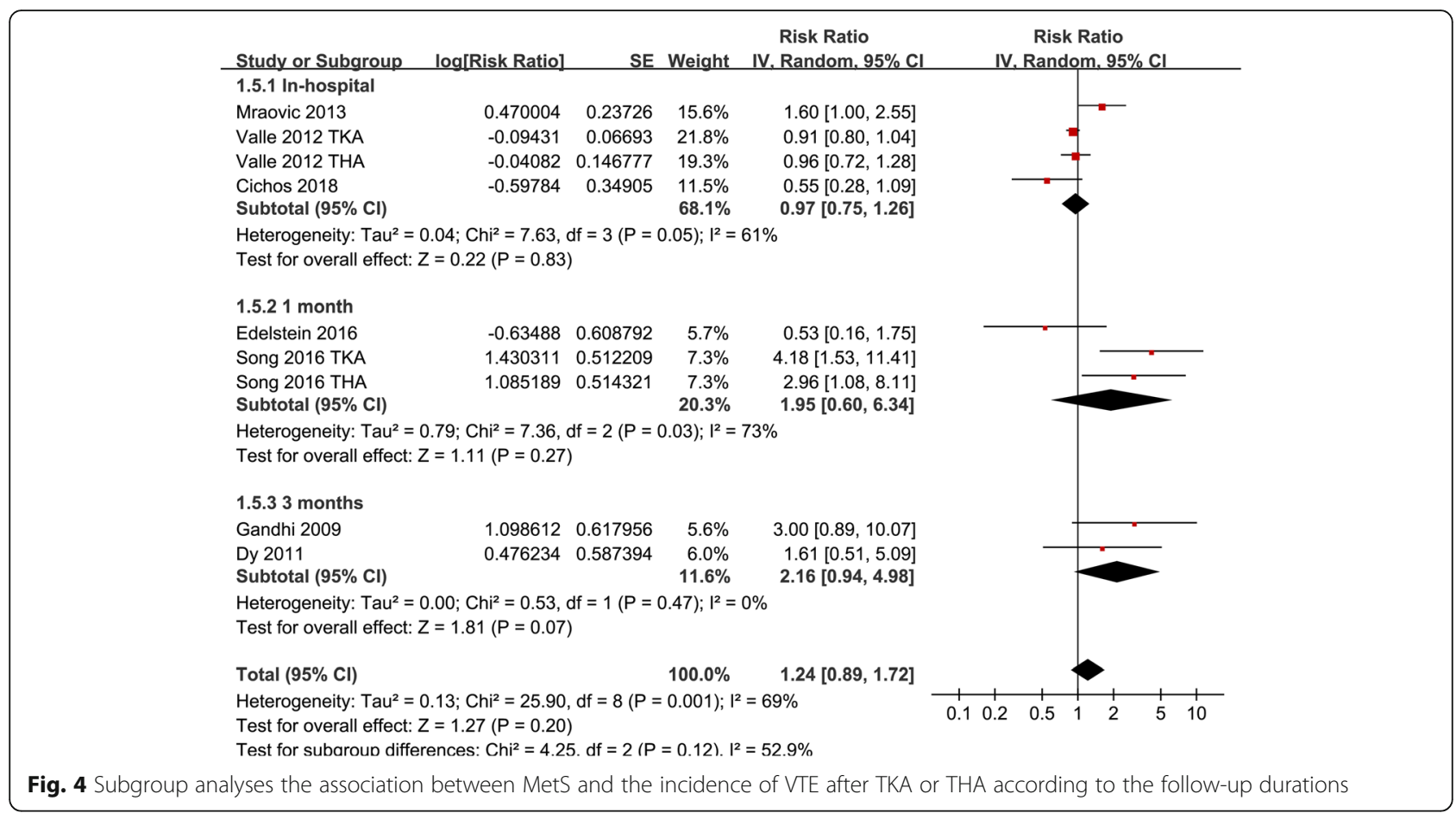

obesity and insulin resistance [31]. However, the correlation of nutritional status and VTE risk could be complex, since recent studies showed that the poor nutrition status was also associated with a high risk of developing DVT, particularly for those who underwent major surgeries [32, 33]. Further studies are needed to elucidate the mechanisms underlying the association between MetS and DVT.

Our study has limitations, which should be considered when interpreting the results. Firstly, as a meta-analysis of observational studies, although we combined RR data after adjustment of potential confounding factors, we

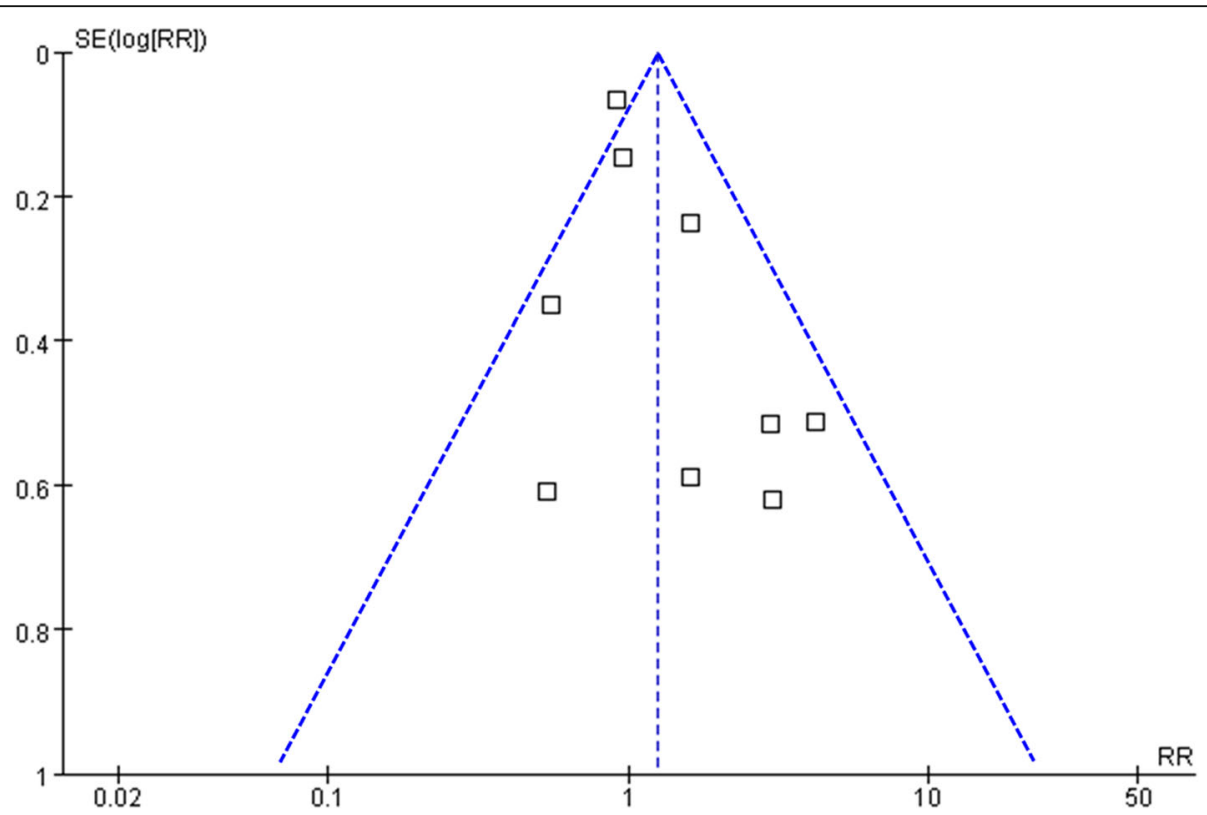

Fig. 5 Funnel plots for the meta-analyses of the association between MetS and the incidence of VTE after TKA or THA 
could not exclude other residual factors that may confound the association between MetS and DVT after TJA, such as the comorbidities of the patients and concurrent medications [34]. Secondly, due to the limited number of the included studies, the result of the subgroup analysis should be interpreted with caution. In addition, most of the included studies were retrospective, which may be limited by the recall bias compared to prospective studies. Moreover, the lengths of follow-up varied among the included studies. However, subgroup analysis showed that MetS was not associated with increased VTE risk after TJA in studies of follow-up within hospitalization, 1 month, and 3 months after JTA. Besides, the long-term (> 3 months) association between MetS and VTE risk after TJA remains to be determined in future studies. Finally, a causative relationship between MetS and increased DVT after TJA should not be retrieved from our results since it is a meta-analysis of observational studies.

\section{Conclusions}

In conclusion, our meta-analysis showed that current evidence from observational studies suggests MetS might increase the risk of DVT but not PE in patients that received TJA. Although these findings should be validated in prospective studies, the results of this meta-analysis may suggest the importance of MetS control for reducing the risk of DVT after TJA.

\section{Abbreviations \\ MetS: Metabolic syndrome; VTE: Venous thromboembolism; DVT: Deep vein thrombosis; PE: Pulmonary embolism; TJA: Total joint arthroplasty; TKA: Total knee arthroplasty; THA: Total hip arthroplasty; WHO: World Health Organization; NCEP-ATP III: Revised National Cholesterol Education Program's Adults Treatment Panel III; MOOSE: Meta-analysis of Observational Studies in Epidemiology; RRs: Risk ratios; SE: Stand error}

\section{Acknowledgements}

Not applicable.

\begin{abstract}
Authors' contributions
YY and JT designed the study. YY and ZL performed the database search, literature review, data extraction, and study quality evaluation. YY and $\mathrm{HL}$ performed the statistical analyses, data interpretation, and drafted the manuscript. JT critically revised the manuscript. The authors reviewed the manuscript and approved its submission.
\end{abstract}

\section{Funding}

Not received.

\section{Availability of data and materials}

The raw data used in our study are included in the manuscript with tables, figures, and its supplementary information files. All the authors agreed that the data could be shared if required by the researchers.

\section{Ethics approval and consent to participate}

All analyses were based on previous published studies; thus, no ethical approval and patient consent are required. All previous published studies were approved by the ethics committee respectively.

\section{Consent for publication}

Not applicable.

\section{Competing interests}

The authors declare that they have no competing interests.

\section{Author details}

'Department of Orthopedic and Joint Surgery, Zhu Jiang Hospital, Southern Medical University, No. 253 Middle Gongye Dadao, Haizhu District,

Guangzhou 510000, China. ${ }^{2}$ Department of Doppler Ultrasonic Department,

Shen Zhen Hospital, Southern Medical University, Shenzhen 518000, China.

Received: 15 May 2020 Accepted: 18 November 2020

Published online: 30 November 2020

\section{References}

1. Trivedi NN, Fitzgerald SJ, Schmaier AH, Wera GD. Venous thromboembolism chemoprophylaxis in total hip and knee arthroplasty: a critical analysis review. JBJS Rev. 2019;7(1):e2.

2. Mula V, Parikh S, Suresh S, Bottle A, Loeffler M, Alam M. Venous thromboembolism rates after hip and knee arthroplasty and hip fractures. BMC Musculoskelet Disord. 2020;21(1):95.

3. Warren JA, Sundaram K, Kamath AF, Molloy RM, Krebs VE, Mont MA, et al. Venous thromboembolism rates did not decrease in lower extremity revision total joint arthroplasty from 2008 to 2016. J Arthroplasty. 2019; 34(11):2774-9

4. Lieberman JR, Heckmann N. Venous thromboembolism prophylaxis in total hip arthroplasty and total knee arthroplasty patients: from guidelines to practice. J Am Acad Orthop Surg. 2017;25(12):789-98.

5. Januel JM, Chen G, Ruffieux C, Quan H, Douketis JD, Crowther MA, et al. Symptomatic in-hospital deep vein thrombosis and pulmonary embolism following hip and knee arthroplasty among patients receiving recommended prophylaxis: a systematic review. JAMA. 2012;307(3):294-303.

6. Shahi A, Bradbury TL, Guild GN 3rd, Saleh UH, Ghanem E, Oliashirazi A. What are the incidence and risk factors of in-hospital mortality after venous thromboembolism events in total hip and knee arthroplasty patients? Arthroplast Today. 2018:4(3):343-7.

7. Weihe P, Weihrauch-Bluher S. Metabolic syndrome in children and adolescents: diagnostic criteria, therapeutic options and perspectives. Curr Obes Rep. 2019;8(4):472-9.

8. Engin A. The definition and prevalence of obesity and metabolic syndrome. Adv Exp Med Biol. 2017;960:1-17.

9. Santilli F, Vazzana N, Liani R, Guagnano MT, Davi G. Platelet activation in obesity and metabolic syndrome. Obes Rev. 2012;13(1):27-42.

10. Mao X, Ait-Aissa K, Lagrange J, Youcef G, Louis H. Hypertension, hypercoagulability and the metabolic syndrome: a cluster of risk factors for cardiovascular disease. Biomed Mater Eng. 2012;22(1-3):35-48.

11. Morange PE, Alessi MC. Thrombosis in central obesity and metabolic syndrome: mechanisms and epidemiology. Thromb Haemost. 2013;110(4): 669-80.

12. Gil JS, Drager LF, Guerra-Riccio GM, Mostarda C, Irigoyen MC, Costa-Hong V, et al. The impact of metabolic syndrome on metabolic, pro-inflammatory and prothrombotic markers according to the presence of high blood pressure criterion. Clinics (Sao Paulo). 2013;68(12):1495-501.

13. Basurto L, Diaz A, Rodriguez A, Robledo A, Vega S, Garcia-Vega J, et al. Circulating levels of plasminogen activator inhibitor-1 are associated with metabolic syndrome rather than with menopause. Gynecol Endocrinol. 2019:1-4.

14. Mottillo S, Filion KB, Genest J, Joseph L, Pilote L, Poirier $\mathrm{P}$, et al. The metabolic syndrome and cardiovascular risk a systematic review and metaanalysis. J Am Coll Cardiol. 2010;56(14):1113-32.

15. Ageno W, Di Minno MN, Ay C, Jang MJ, Hansen JB, Steffen LM, et al. Association between the metabolic syndrome, its individual components, and unprovoked venous thromboembolism: results of a patient-level metaanalysis. Arterioscler Thromb Vasc Biol. 2014;34(11):2478-85.

16. Gandhi R, Razak F, Tso P, Davey JR, Mahomed NN. Metabolic syndrome and the incidence of symptomatic deep vein thrombosis following total knee arthroplasty. J Rheumatol. 2009;36(10):2298-301.

17. Dy CJ, Wilkinson JD, Tamariz L, Scully SP. Influence of preoperative cardiovascular risk factor clusters on complications of total joint arthroplasty. Am J Orthop (Belle Mead NJ). 2011;40(11):560-5.

18. Gonzalez Della Valle A, Chiu YL, Ma Y, Mazumdar M, Memtsoudis SG. The metabolic syndrome in patients undergoing knee and hip arthroplasty: 
trends and in-hospital outcomes in the United States. J Arthroplasty. 2012; 27(10):1743-9 e1.

19. Mraovic B, Hipszer BR, Epstein RH, Parvizi J, Pequignot EC, Chervoneva I, et al. Metabolic syndrome increases risk for pulmonary embolism after hip and knee arthroplasty. Croat Med J. 2013;54(4):355-61.

20. Edelstein Al, Suleiman LI, Alvarez AP, Sacotte RM, Qin CD, Beal MD, et al. The interaction of obesity and metabolic syndrome in determining risk of complication following total joint arthroplasty. J Arthroplasty. 2016;31(9 Suppl):192-6.

21. Song $K$, Rong Z, Yao Y, Shen Y, Zheng M, Jiang Q. Metabolic syndrome and deep vein thrombosis after total knee and hip arthroplasty. J Arthroplasty. 2016;31(6):1322-5.

22. Cichos KH, Churchill JL, Phillips SG, Watson SL, McGwin G Jr, Ghanem ES, et al. Metabolic syndrome and hip fracture: epidemiology and perioperative outcomes. Injury. 2018:49(11):2036-41.

23. Stroup DF, Berlin JA, Morton SC, Olkin I, Williamson GD, Rennie D, et al. Meta-analysis of observational studies in epidemiology: a proposal for reporting. Meta-analysis Of Observational Studies in Epidemiology (MOOSE) group. JAMA. 2000;283(15):2008-12.

24. Higgins J, Green S. Cochrane Handbook for Systematic Reviews of Interventions Version 5.1.0. The Cochrane Collaboration. 2011;www. cochranehandbook.org.

25. Wells GA, Shea B, O'Connell D, Peterson J, Welch V, Losos M, et al. The Newcastle-Ottawa Scale (NOS) for assessing the quality of nonrandomised studies in meta-analyses. 2010;http://www.ohri.ca/programs/_linical_ epidemiology/oxford.asp.

26. Higgins JP, Thompson SG. Quantifying heterogeneity in a meta-analysis. Stat Med. 2002;21(11):1539-58.

27. Egger M, Davey Smith G, Schneider M, Minder C. Bias in meta-analysis detected by a simple, graphical test. BMJ. 1997;315(7109):629-34.

28. Sloan M, Sheth N, Lee GC. Is obesity associated with increased risk of deep vein thrombosis or pulmonary embolism after hip and knee arthroplasty? A large database study. Clin Orthop Relat Res. 2019;477(3):523-32.

29. Zmistowski B, Dizdarevic I, Jacovides CL, Radcliff KE, Mraovic B, Parvizi J. Patients with uncontrolled components of metabolic syndrome have increased risk of complications following total joint arthroplasty. J Arthroplasty. 2013;28(6):904-7.

30. Xie W, Zhai Z, Yang Y, Kuang T, Wang C. Free fatty acids inhibit TM-EPCR expression through JNK pathway: an implication for the development of the prothrombotic state in metabolic syndrome. J Thromb Thrombolysis. 2012;34(4):468-74.

31. Sanchez C, Poggi M, Morange PE, Defoort C, Martin JC, Tanguy S, et al. Diet modulates endogenous thrombin generation, a biological estimate of thrombosis risk, independently of the metabolic status. Arterioscler Thromb Vasc Biol. 2012;32(10):2394-404

32. e S, Yamato Y, Hasegawa T, Yoshida G, Kobayashi S, Yasuda T, et al. Association between a prognostic nutritional index less than 50 and the risk of medical complications after adult spinal deformity surgery. J Neurosurg Spine. 2020:1-6. https:/doi.org/10.3171/2020.1.SPINE191410. Online ahead of print.

33. Iguchi T, Sugimachi K, Mano Y, Kono M, Kagawa M, Nakanoko T, et al. The preoperative prognostic nutritional index predicts the development of deep venous thrombosis after pancreatic surgery. Anticancer Res. 2020;40(4): 2297-301.

34. Landy DC, Bradley AT, King CA, Puri L. Stratifying venous thromboembolism risk in arthroplasty: do high-risk patients exist? J Arthroplasty. 2020;35(5): 1390-6.

\section{Publisher's Note}

Springer Nature remains neutral with regard to jurisdictional claims in published maps and institutional affiliations.

Ready to submit your research? Choose BMC and benefit from:

- fast, convenient online submission

- thorough peer review by experienced researchers in your field

- rapid publication on acceptance

- support for research data, including large and complex data types

- gold Open Access which fosters wider collaboration and increased citations

- maximum visibility for your research: over $100 \mathrm{M}$ website views per year

At $\mathrm{BMC}$, research is always in progress.

Learn more biomedcentral.com/submissions 